\title{
Modeling ecotourism potentials of karst springs in GIS environment: A case study of Rijab mirage in Kermanshah province, Iran
}

\author{
Behrouz Nasiri, Mostafa Karampoor, Parsa Gholami", Shoaib Abkharabat, Siamak Ahmadi \\ Department of Geographical science, Lorestan University, Lorestan, Iran
}

\section{Email address:}

behrouz.nasiri46@gmail.com (B. Nasiri),karampoor.m@lu.ac.ir (M. Karampoor), parsagholami83@yahoo.com (P. Gholami), kharabatian@yahoo.com (S. Abkharabat), siamakahmadi_tmu@yahoo.com (S. Ahmadi)

\section{To cite this article:}

Behrouz Nasiri, Mostafa Karampoor, Parsa Gholami, Shoaib Abkharabat, Siamak Ahmadi. Modeling Ecotourism Potentials of Karst Springs in GIS Environment: A Case Study of Rijab Mirage in Kermanshah Province, Iran. Earth Sciences. Vol. 4, No. 1, 2015, pp. 39-49.

doi: $10.11648 /$ j.earth. 20150401.14

\begin{abstract}
Mirages of Kermanshah province of Iran including Rijab mirage, with unique features such specific animal and plant species, very suitable climate, roaring waterfalls and etc. currently, as a ecotourism region is used by so Many people And has the capacity to become an ecotourism zone in the province and the country. In this research for feasibility of ecotourism development in mentioned area, first in the identification process, ecologically sustainable sources including vegetation cover, soil, geology and geomorphology has been identified And then in summarization and analysis step data obtained from the previous step, were processed and classified to enter in GIS environment; land surveying was conducted and then it combined with soil map and vegetation cover maps, ecological unit map, which is the base of ecological assessment, is obtained. Unsustainable resources such as water, climate and etc. were also considered.
\end{abstract}

Keywords: Sustainable Ecologic, Unsustainable Ecologic, Centralized Ecotourism, Extensive Ecotourism, Mirage

\section{Introduction}

Kermanshah Province is one of the most historical areas of Iran that have Mountain temperate climate and picturesque and diverse landscapes specially Mirage and numerous springs. Explanation of natural potentials of Mirages for ecotourism and providing necessary projects are geographer's tasks And negligence in this case, will cause ignoring applicable role of geography. Study of physical resources (climate, rocks, soil, form of land), and biological resources (plant) is essential to recognize power and natural potentials of Mirage in any area. Although mirages of our country with great features and geographically diverse perspectives have actual and potential power for attracting ecotourist, but unfortunately, many of these potentials have not been used properly. Certainly with a comprehensive knowledge, designing, proper preparation and management, sustainable development program can be achieved and ecological crises that threaten the ecosystems and humans, can be avoided. In modeling and evaluation step, with creating the ecotourism model in compliance with national and international standards, the zoning map of ecotourism and its classes were conducted. Thus some zones for extensive and centralized ecotourism were introduced.

\section{Literature}

This study, like other research studies are designed according to three main aspects: Identifying existing situations and conditions, Identifying situations and opportunities of research and their analysis, and Planning for optimal utilization of the situations and opportunities, with emphasis on the principles and objectives of sustainable development, So In the first stage human and natural conditions of the study area are identified and analyzed then natural features and attractions of study area as a combination of Attractions, and also Mirage position in each of obtained zones are determined by the synthesis of thematic maps. Classified thematic maps of climate, soil, vegetation cover, elevation, slope, etc. are provided as level of information and through the synthesis of two criteria (two of two) will be synthesized and finally ecotourism potential of each zone is determined. Also role and place of Mirages as independent or dependent ecosystems are identified and can 
be used in planning. In the final stage, based on existing characteristics and potential regional capacities, in order to exploit the ecotourism, required planning is done.( Ahmadi, 2000)

Ecological resources in a major division can be divided into two types, sustainable and sustainable resources. Sustainable ecological resources are resources that are fixed in place. These resources include:

- Rocks

- land form and geomorphology

- Soil

- Plants

Such changes in resources, if does not affected by natural and human extreme force, often will become slow per unit time. Unsustainable ecological resources, are resources that are not fixed in place, changes in these resources are fast per unit time. Unsustainable ecological resources include:

- Climate

- Water resources

Sustainable Resources have important role in evaluating the potential for various applications. To identify the source of each categorization of resources according to the situation of the study area, the surveying will need to include:

- Slope map

- elevation map

- Preparation of geographical indirections

- Land form unit map

- Geomorphologic map

- Soil map (land use map)

- Density map of vegetation cover

To prepare tabular drawings, driving directions and height from sea surface, at first topographic map of the area where its level lines have been digitized, is recorded in computer as an informational layer. Then, from these informational layers, by the GIS command functions, tabular drawings, aspect, and elevation are prepared. (Zendehdel, 2000)

\section{Materials and Methods}

\subsection{Preparation Method of Land form Unit Maps}

Land form includes natural units and each unit under the same conditions of: climate, weathering, erosion and evolved mass deposition, has turned into the current form. So soils which are formed in a land unit and on a specific rock, and in a similar situation, have similarity; their physical properties are also similar, so the land form reveals Soil and herb on it. In this case, by understanding the form of the land we can realize them and its potential for land using. According to what stated, each land form unit displays a large ecosystem. (Makhdom, 2005)

Among parameters of the land form which sometimes includes up to eight different items, only by knowing the three parameters slope, height from sea surface, and geographical indirections, land form of area can be identified.

So for mapping units of land form, first land form must be decomposed into its main components, including the slope, height from sea surface, and geographical indirections. In prior phase, this work was done with preparing Floor Plans of above items. Now it is necessary that each of these components are combined to present a unique units of land form. To combine these components first, floor plan of height from sea surface is placed on floor plan of tabular drawing. And after obtaining the new map which is called a" Preliminary plan of land form units", it will be placed on floor plan of geographical indirections map at last and the final plan of land form units is obtained.

In fact in this map, various units of land that is different in terms of floor elevation, slope, And geographical directions are identified. (Darvishsefat et al, 2004).In obtained map (fig 1-15), each unit contains three characteristics: slope, aspect, elevation.

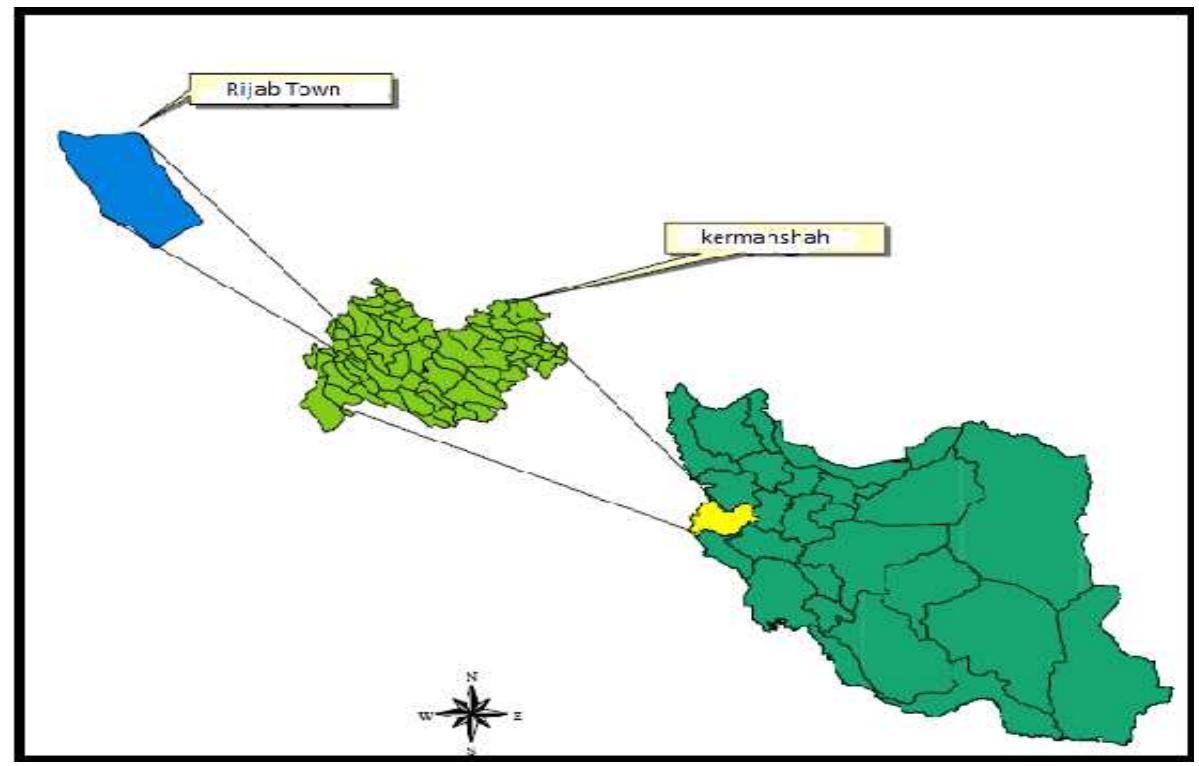

Figure 1. Rijab Mirage Basin Map. 


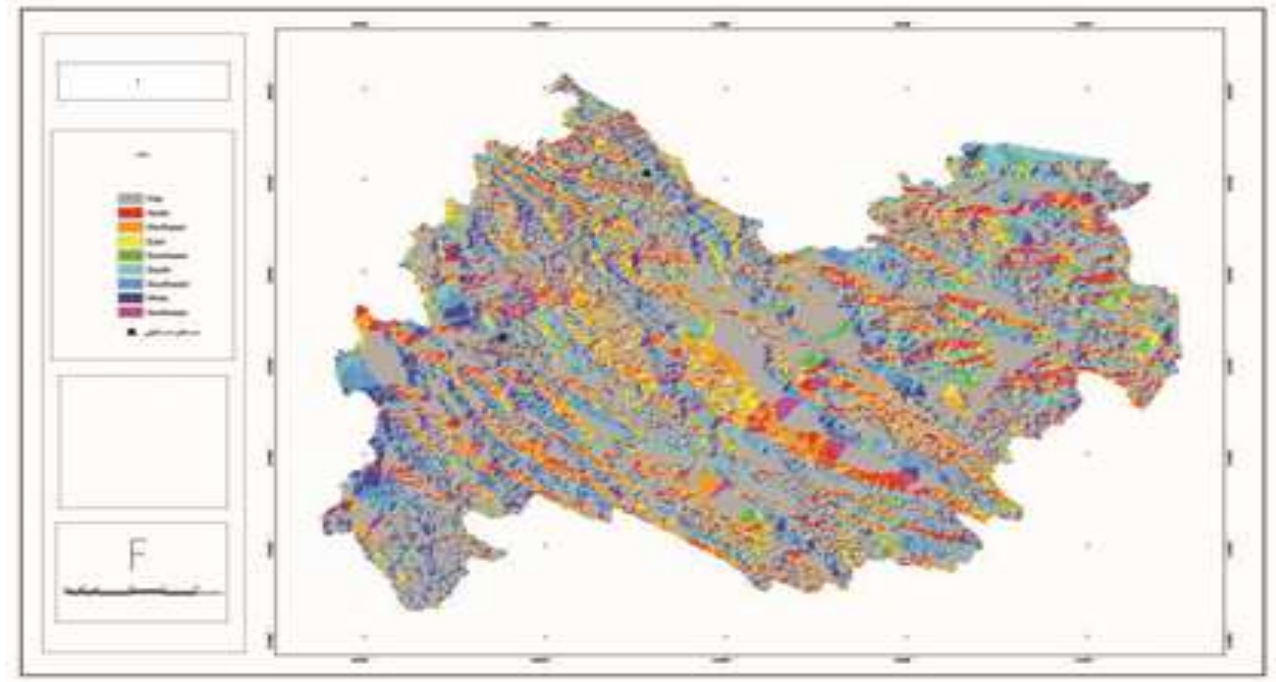

Figure 2. Geographical Indirections Map.

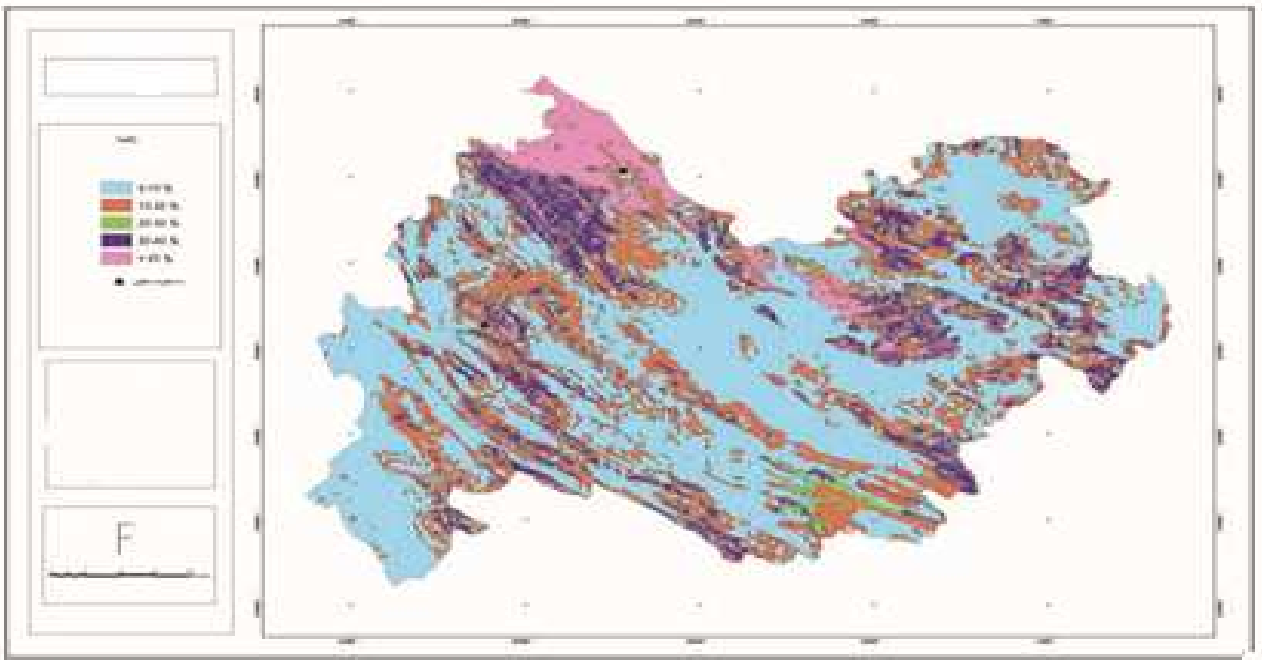

Figure 3. slope map.

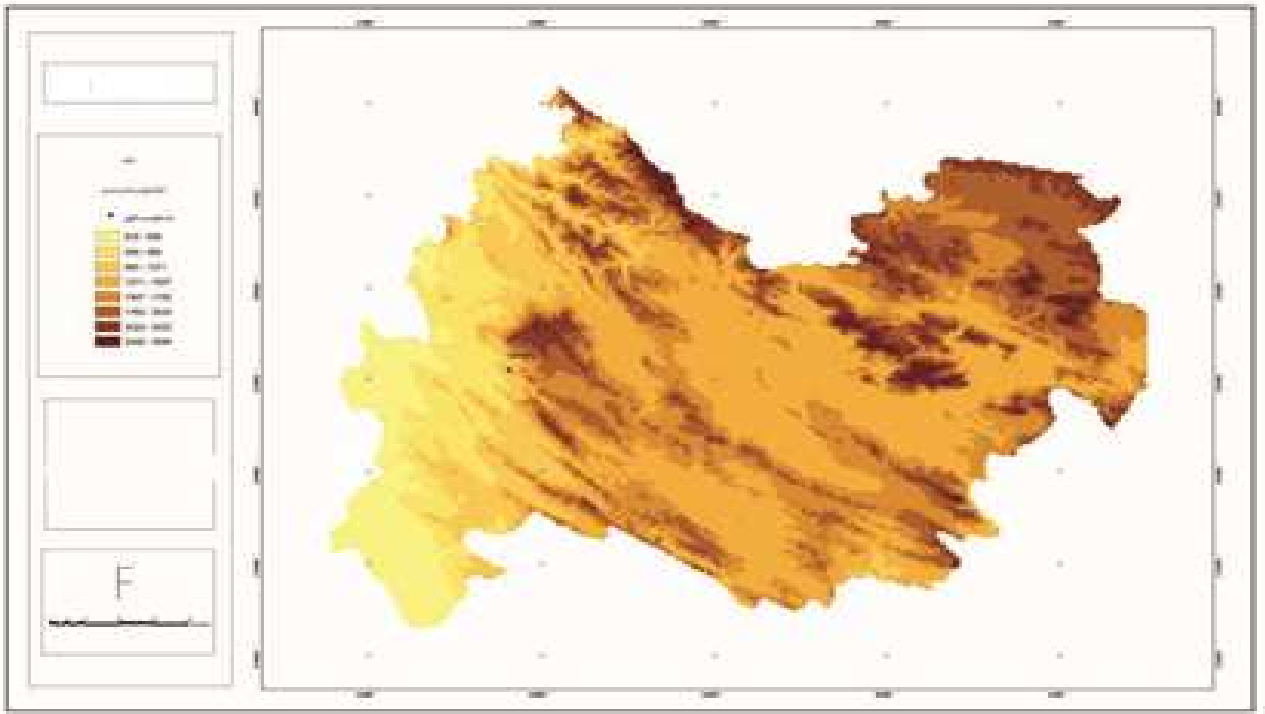

Figure 4. Height from Sea Surface Map. 


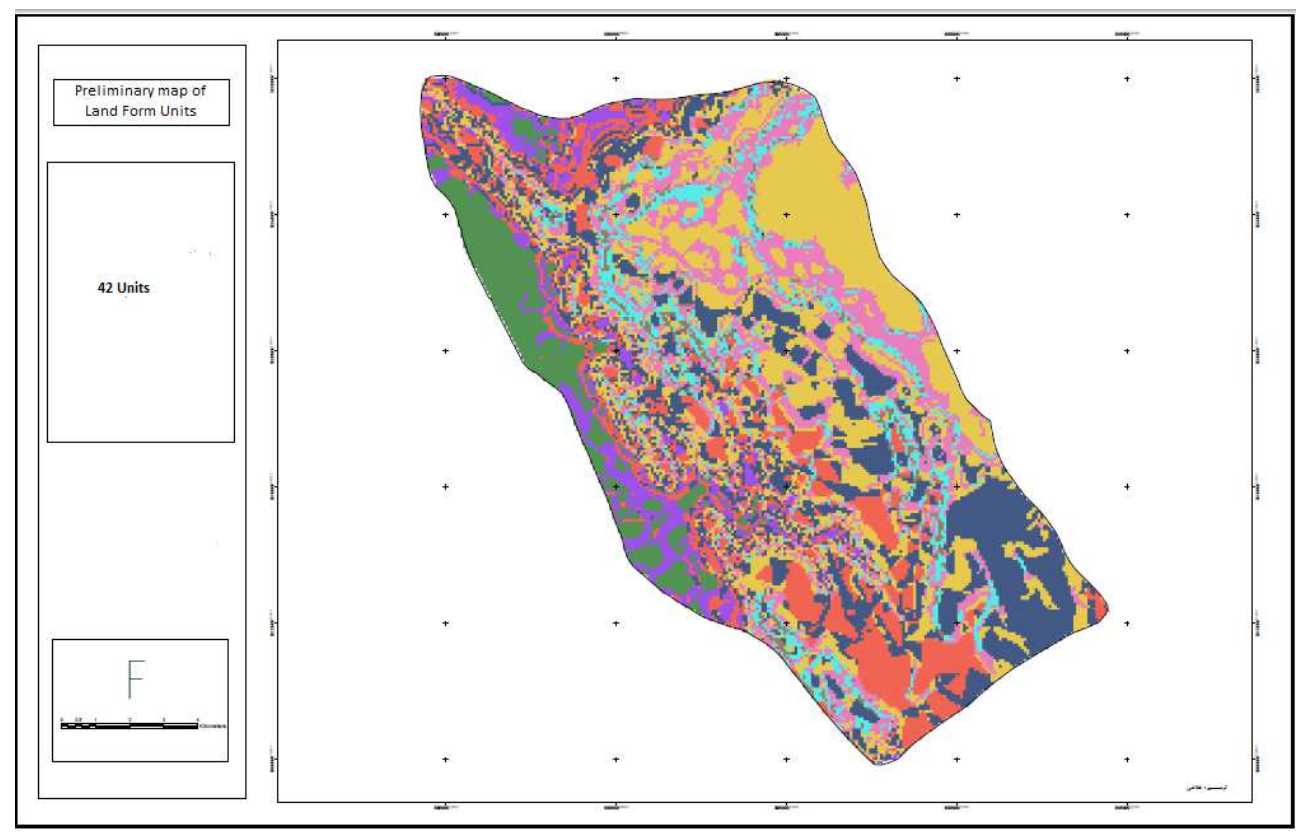

Figure 5. Preliminary map of Land Form Units.

\subsection{Zoning for Mapping Unit}

The data that we import into Geographic Information System (GIS) cannot be rawly used for assessment and planning. Data whether maps or tables, are spread out such that without integration are confusing. Thus, processed data must be analyzed. Then, depending on the purpose, should be interpreted and eventually turn into regular groups.

Analysis and interpretation of data, for integration in geographic information systems, consider Geographic information as finding a template or pattern of similar and homogenous structures among the entered data. These similar and homogenous structures for assessment and planning are Mapping Unit (MU).

Mapping Unit for assessment and land planning is called Ecological Unit, and it can be justified as a micro ecosystem. (Makhdom, 2005)

Because the obtained ecological unit, is derived from combining a large number of ecological parameters it can show land capability much better. Therefore zoning method for mapping unit (ecological unit) is performed to achieve the same or homogeneous data structures on the map (which represents the spatial aggregation of the data set). Thus, following the conclusion of the data, with questions and answers or foremost with a molding, it is easier and more accurate and faster to evaluate the need for planning and finally make decision. (Ibid)

\subsection{Mapping Ecological Units with GIS}

Ecological unit mapping is done in several steps, including: First step: From overlaying maps of land form units (Fig. 6) to soil map (Fig.7) unit's first ecological base map (Fig.8) is obtained.

This map contains 815 units that each unit has four different parameters of slope, aspect, elevation, and soil.
Second step: From overlaying soil map (Fig.7) to vegetation cover map (Fig.9) final unit map (Fig.10) is obtained

This map contains 928 new units without repetition which each unit includes five parameters of slope, aspect, elevation, soil, and vegetation cover.

It is noted that in each step according to Area of a Region, units that have less than one hectare area, were merged in adjacent units Because of the small number of these units, the overlaying in the next steps could be difficult, and they had little effect on the assessment and planning. (Afshar sistani, 1992)

Up to this stage, to get ecological unit plan, sustainable resources' plans were used. But in ecologically unsustainable resource use, only overlaying act is done but there is no zoning for mapping, only ecological units table was overlaid by storage of thematic map information. Among unsustainable Ecological sources in this study, natural resources that are important for modeling of ecotourism has been classified (tables 1, 2, 3, and figures 11, 12, and 13)

Table 1. surface precipitation.

\begin{tabular}{ll}
\hline class & Average annual precipitation(mm) \\
\hline 1 & $200-300$ \\
2 & $300-400$ \\
3 & $400-500$ \\
4 & $500-600$ \\
5 & $600-700$ \\
6 & $700-800$ \\
7 & $800-900$ \\
8 & $900-1000$ \\
\hline
\end{tabular}


Table 2. surface Temperature.

\begin{tabular}{ll}
\hline Class & Average annual Temperature $\left({ }^{\circ} \mathbf{C}\right)$ \\
\hline 1 & Less than 7.5 \\
2 & $7.5-10$ \\
3 & $10-12.5$ \\
5 & $12.5-15$ \\
6 & $15-17.5$ \\
7 & $17.5-20$ \\
8 & $20-22.5$ \\
\hline
\end{tabular}

\begin{tabular}{ll} 
& Table 3. surface evaporation. \\
\hline class & Average annual evaporation $(\mathbf{m m})$ \\
\hline 1 & $1800-1600$ \\
2 & $1800-2000$ \\
3 & $2000-2200$ \\
4 & $2200-2400$ \\
5 & $2400-2600$ \\
6 & $2600-2800$ \\
7 & $2800-3000$ \\
\hline
\end{tabular}

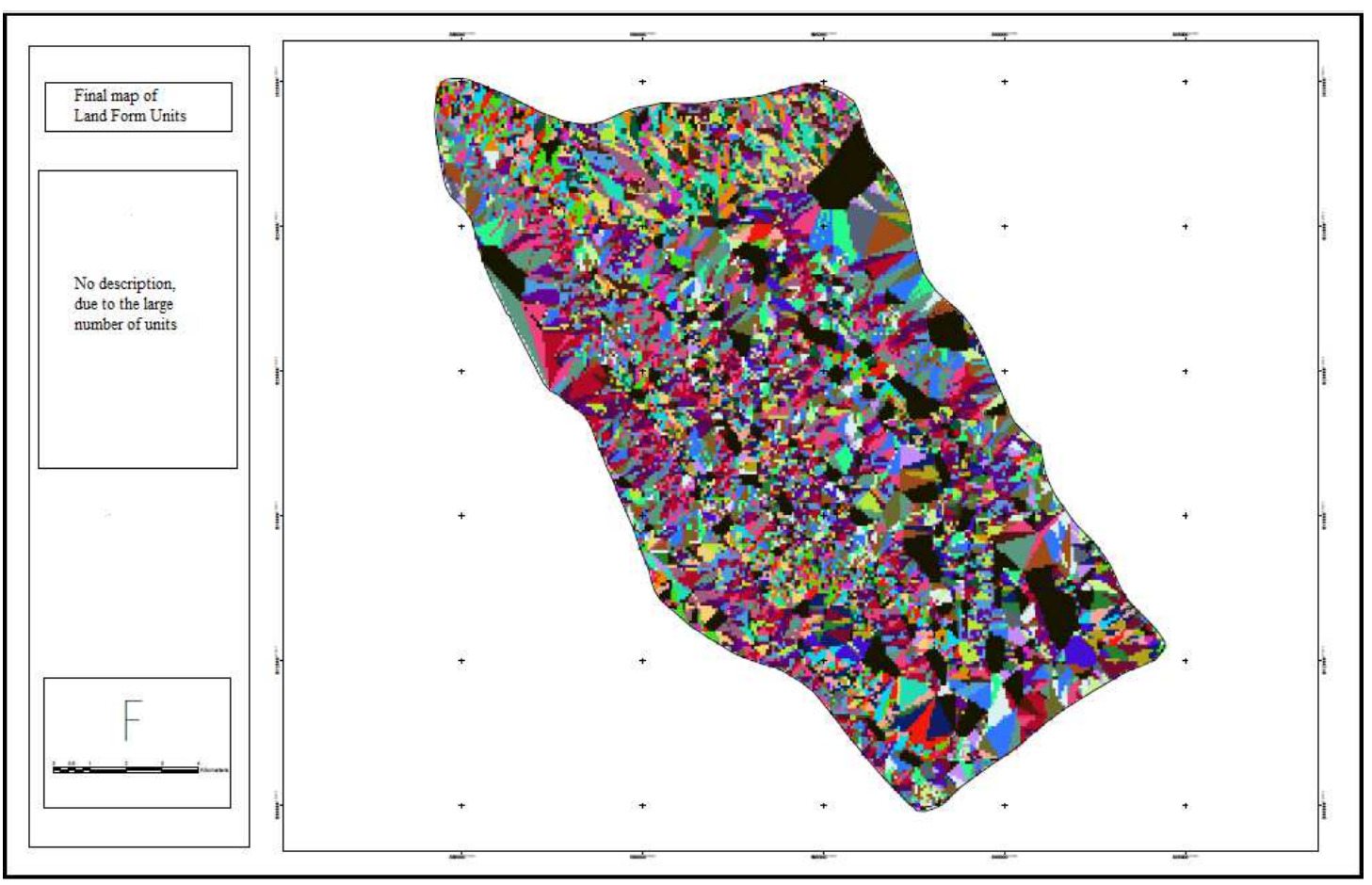

Figure 6. Final map of Land Form Units

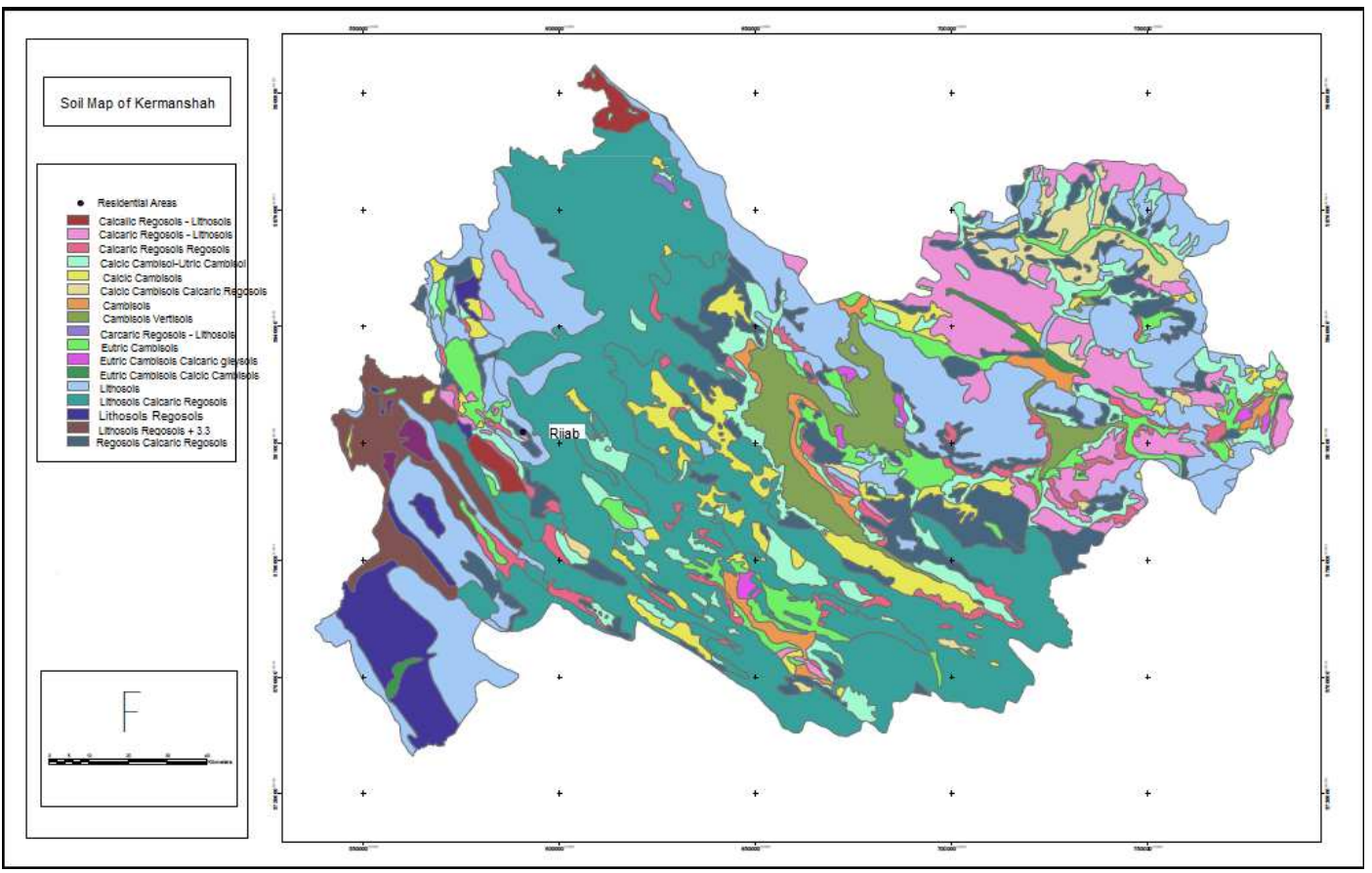

Figure 7. Soil Map. 


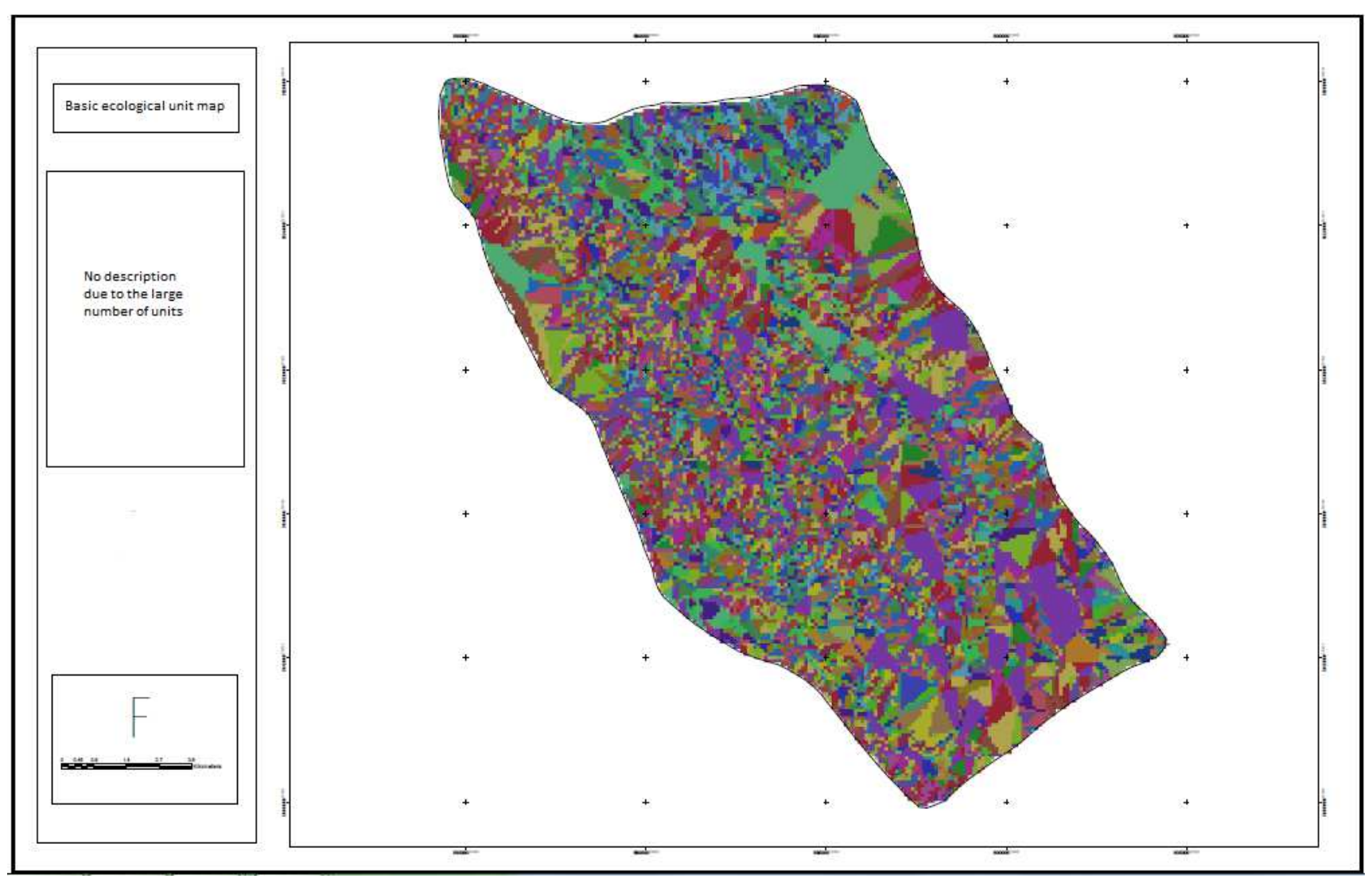

Figure 8. Basic map of ecological units.

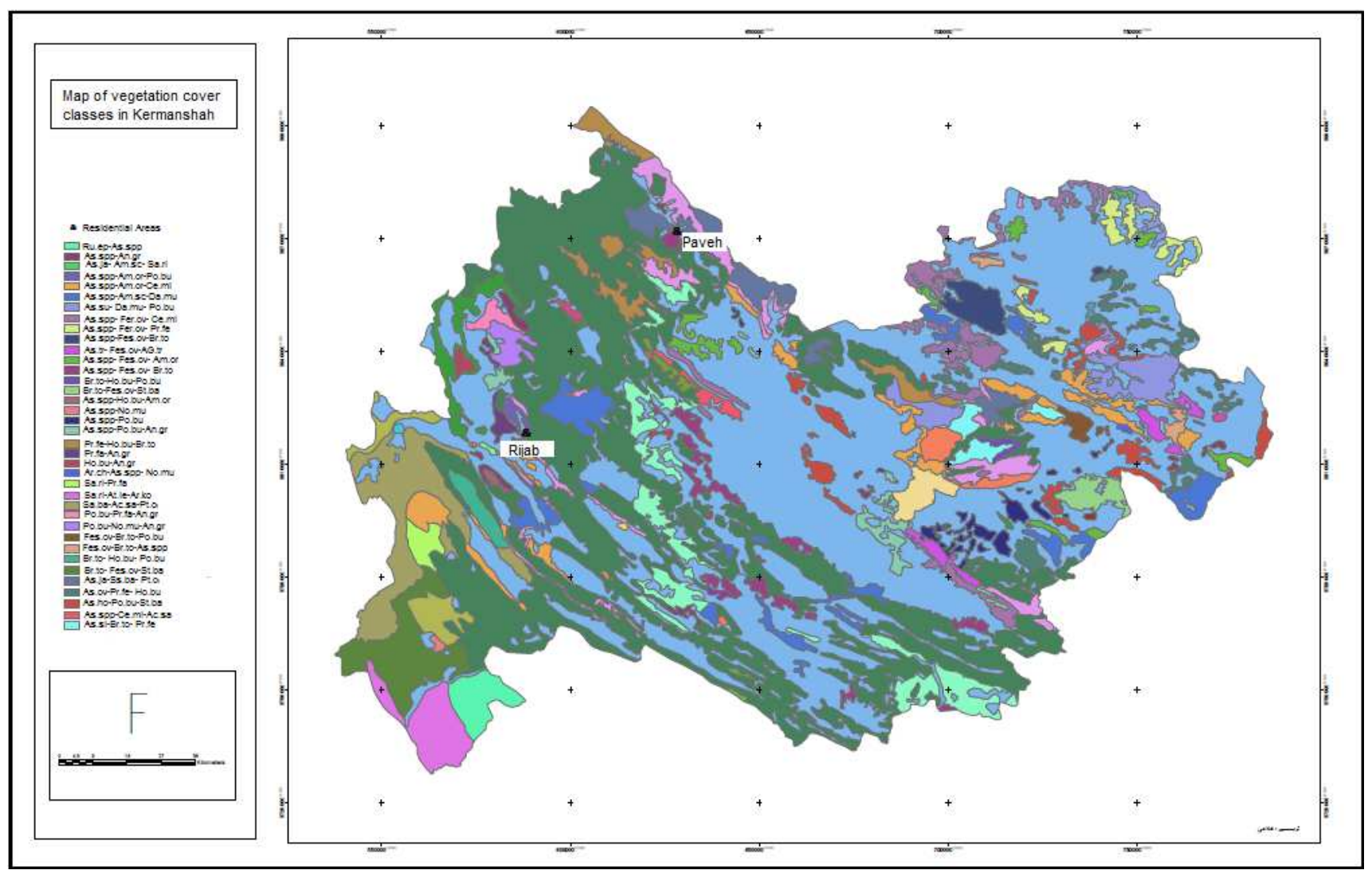

Figure 9. Vegetation cover Map. 


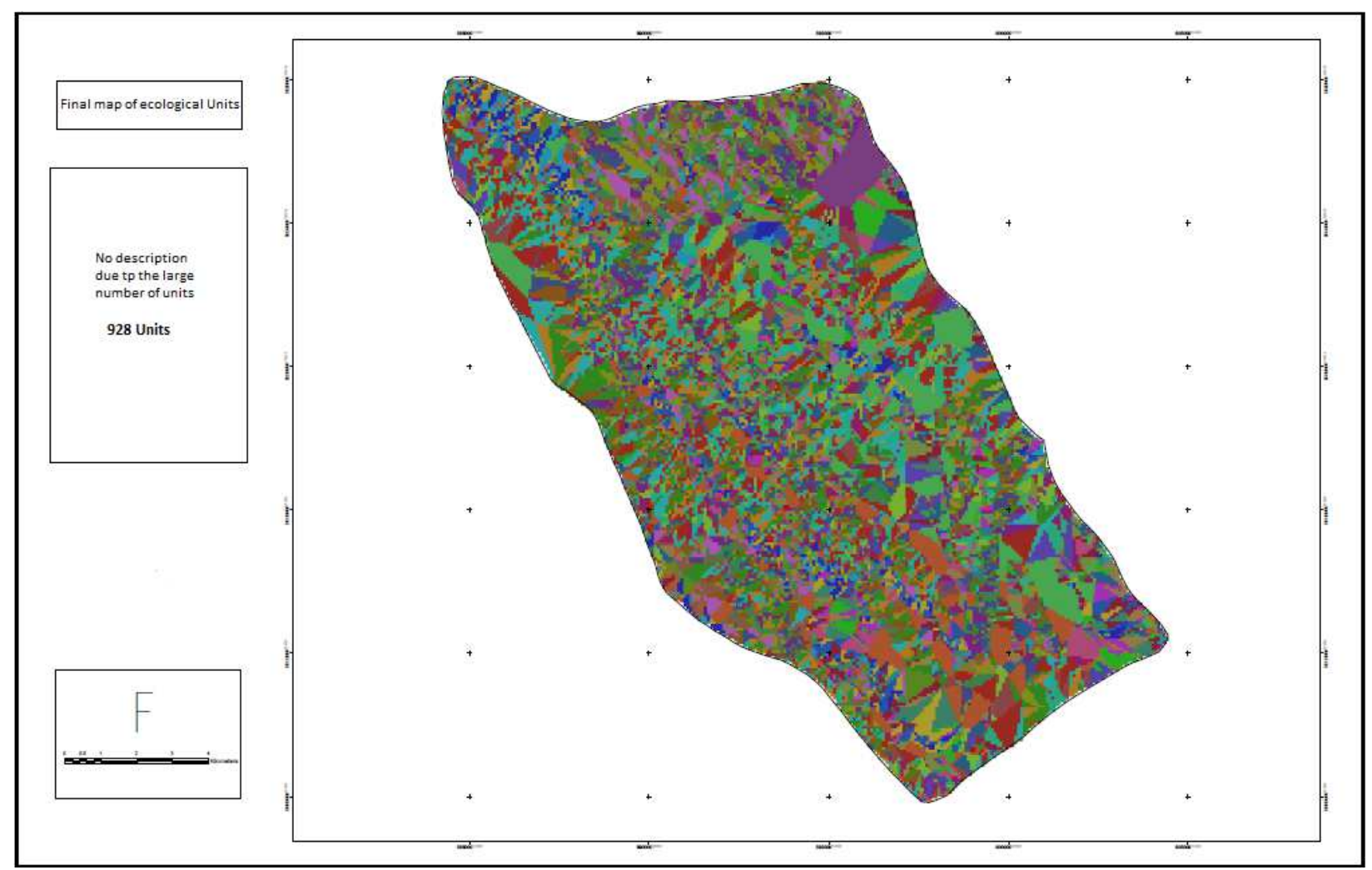

Figure 10. Final map of ecological Units.

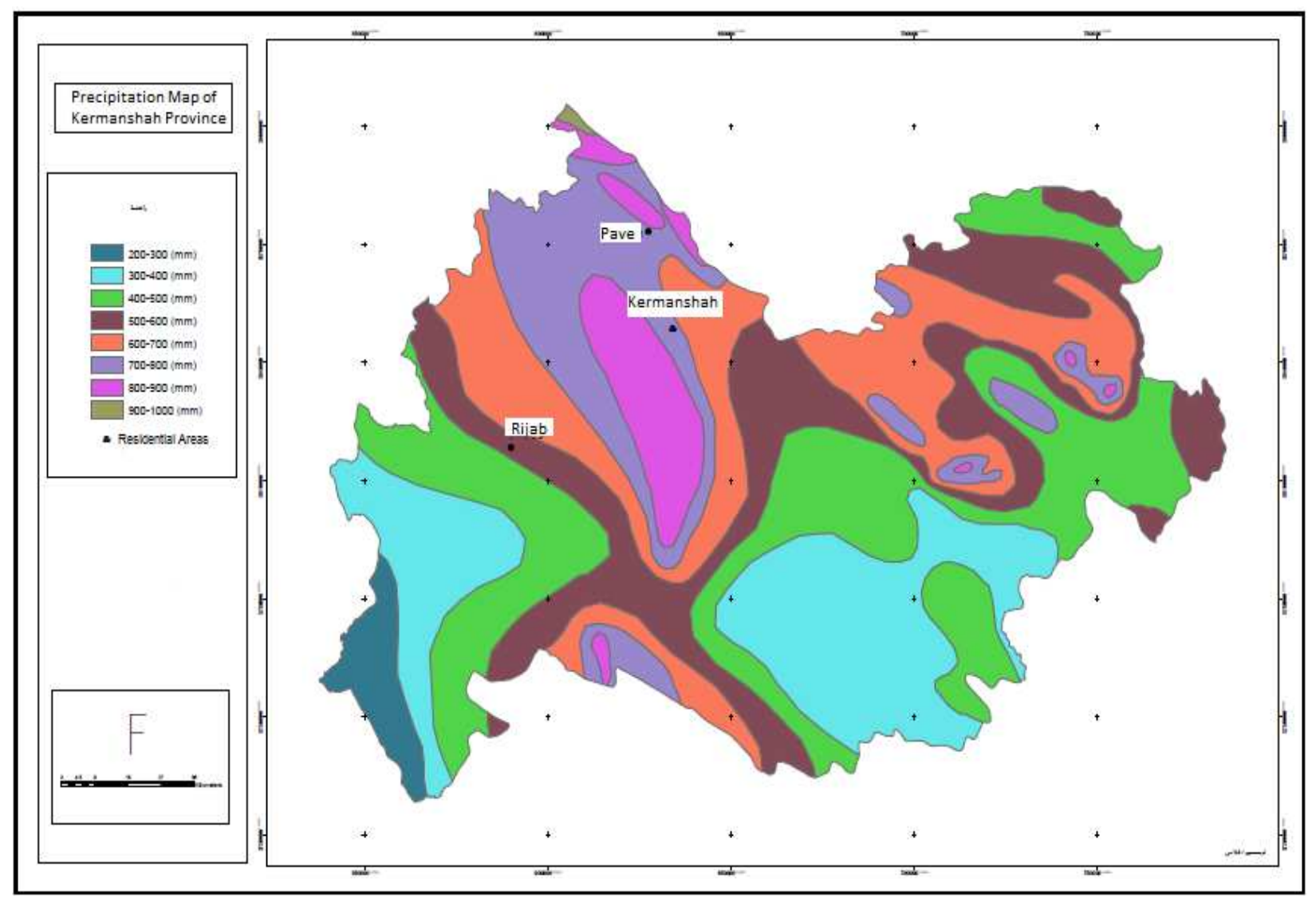

Figure 11. Surface precipitation map. 


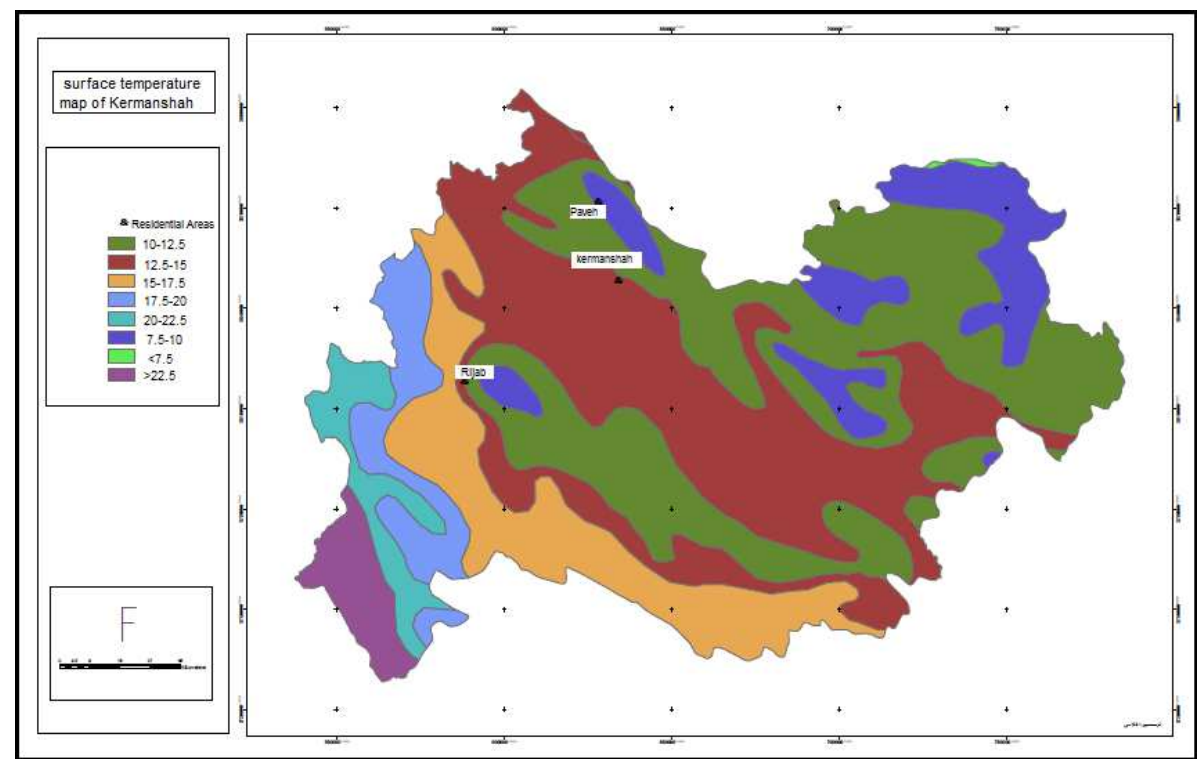

Figure 12. Surface temperature map.

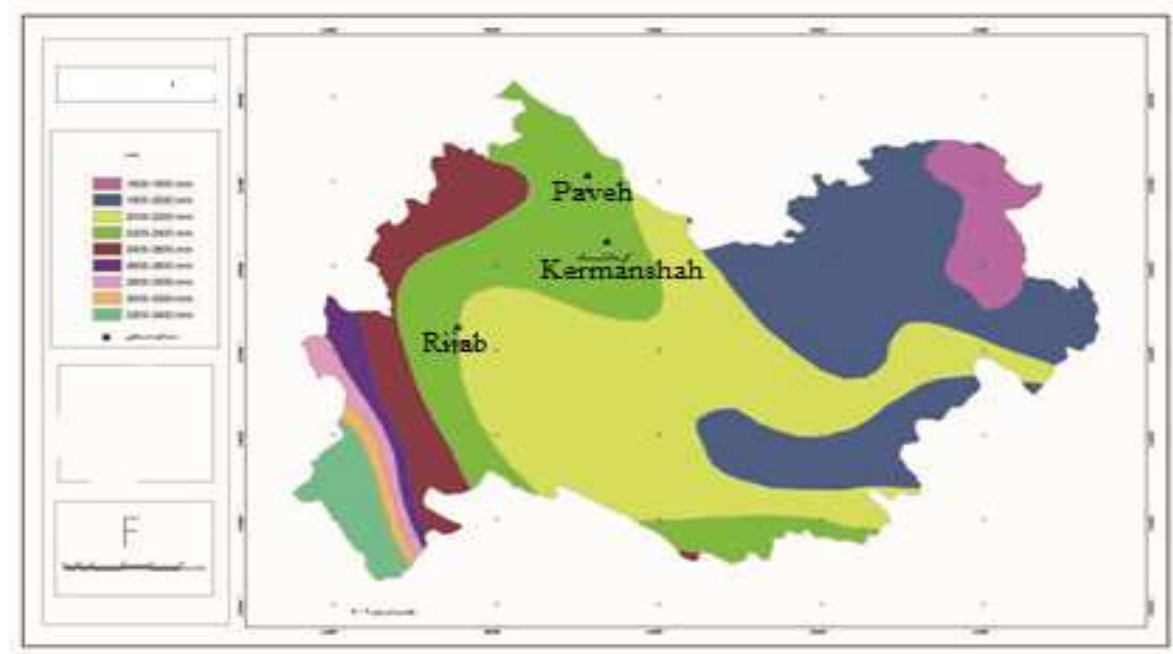

Figure 13. Surface evaporation map.

\subsection{Modeling}

Decision-making model is expression of the link between the quantity and quality of part of the universe, as physical or mathematical in a way that represents an entity or phenomenon in the real world. These models describe the relationship between real-world data to predict how events are.(Makhdom, 2005)

The modeling is done in order that:

- The complexity of the system be easier to be understood

- Having summary of the collected information to be consistent with the nature of data

- Having simulation from Integration of correct existing information to have similarity with real world.

Ecological models in Iran have the following features:

- For everything (except Agricultural and Range Management), a separate model is produced.

- Ecological models have been developed for Multicriteria evaluation.
- Existence of multiple occurrences in ecological unit implies that land capability should take for the specified use.

- Ecological models agree with this rule that to represent the best land use, having improved situation in ecological parameters of land is a necessary condition.

- The basic condition to determine capability with these models is considering nature capability, In other words, these models can show the potential of the natural environment.

- Ecological models show the capability of land as well as the degree of quality. Hence use of ecological models of Iran, assessing and classification of the land are done together.

- Classification of potentials in Ecological models has been done according to the situation of all of Iran not to the local conditions of a region or watershed. (Makhdom, 2005)

Therefore, the evaluation and classification of land / 
environment in Iran is obtained by comparison of ecological characteristics of each ecological unit with ecological model.

\subsubsection{Intensive Outing Model}

Those outing which need to be developed such as swimming, skiing, camping, bike racing, and visiting cultural monuments

a) First class

- Climate and weather: Average temperature of 21-25 ${ }^{\circ}$ $\mathrm{C}$ in spring and summer season. Number of sunny days per year, in spring and summer season is more than 15 days in a month.

- Water: 20 to 150 liters per day for each person

- Percent of Slope: zero to 5

- Geographical Direction: east (in summer), south (in winter)

- Soil texture: loam

- Soil drainage conditions: complete

- Soil fertility: Moderate to good

- Soil structure: semi-developed to developed with moderate graining

- Soil depth: deep

- Mother rock: granite, sand dunes (in humid climate), Basaltic Magmas, alluvial (alluvial deposits in New plateau)

- Tree density: 40-80 percent

- Species Composition: monocots

b) Second class

- Climate and weather: Average temperature of 21-30 $\mathrm{C}$ in spring and summer season. Number of sunny days per year, in spring and summer season is 7-15 days in a month.

- Water: 12 to 40 liters per day for each person

- Percent of Slope: 5-15

- Geographical Direction: north (in summer), west(in winter)

- Soil texture: Sand, sandy clay loam, loamy clay

- Soil drainage conditions: semi complete

- Soil fertility: poor to moderate

- Soil structure: semi-developed to developed with semi-medium coarse graining

- Soil depth: medium to deep

- Mother rock: Sandstone, limestone, fractured tuffs, biostratigraphic magmas, Schist, loess, floodplains, alluvial fans and valley maker alluvium

- Tree density: 20-40 percent

- Species Composition: monocots and dicots, almost equal

c) Inappropriate class

- Water: less than 5 liters per day for each person

- Percent of Slope: more than 15

- Geographical Direction: South and West (in summer and spring), east and north (in winter)

- Soil texture: Heavy loess and hydromorphic soils
- Soil drainage conditions: incomplete

- Soil fertility: very poor

- Soil structure: Tiny graining

- Soil depth: low to high

- Tree density: 20-40 percent

- Species Composition: dicots, fodder plants, woody and thorny shrubs, or slow growth plants

\subsubsection{Extensive Outing Model}

Those outing which do not need to be developed such as such as hiking and hunting, or need a little development, such as fishing, horse riding and watching animals in nature.

a) First class

Climate and weather: Average temperature of $21-25^{\circ} \mathrm{C}$ in spring and summer season. Number of sunny days per year, in spring and summer season is more than 15 days in a month.

Water: 5-12 liters per day for each person

Percent of Slope: zero to 25

Soil and rock conditions: like first class of intensive outing (it is important Only for paths and sidewalks, otherwise soil parameters are not important for extensive outing)

Other parameters have no main importance.

b) Second class

Climate and weather: Average temperature of $21-30{ }^{\circ} \mathrm{C}$ in spring and summer season. Number of sunny days per year, in spring and summer season is 7-15 days in a month.

Water: almost 5 liters per day for each person

Percent of Slope: $25-50$ percent

Soil and rock conditions: like second class of intensive outing (it is important only for paths and sidewalks, otherwise soil parameters are not important for extensive outing)

Other parameters have no main importance

c) Inappropriate class

Percent of Slope: more than 50 percent (except Climbing). (makhdom, 2005)

To assess ecological potential of environment for tourism, all of the above parameters in the ecological model are not the same weight. Parameters' Priority in terms of importance is as follows, respectively: Slope, rock and soil, geographical directions, water and climate. This rule means that if the slope of the environment for the outing was not good, other parameters should be refused to be compared and evaluation will be stopped. (Ranjbarian, 2000)

\section{Results}

The results in this article represents the fact that, given the values and standards recommended by the International Ecotourism facilities and Iran's Cultural Heritage Organization and Touring, mirages of the province especially Rijab mirage, have considerable potential in ecotourism. The results of the analysis of ecological resources and the appropriate zoning maps $(14,15)$ indicate this potential. 


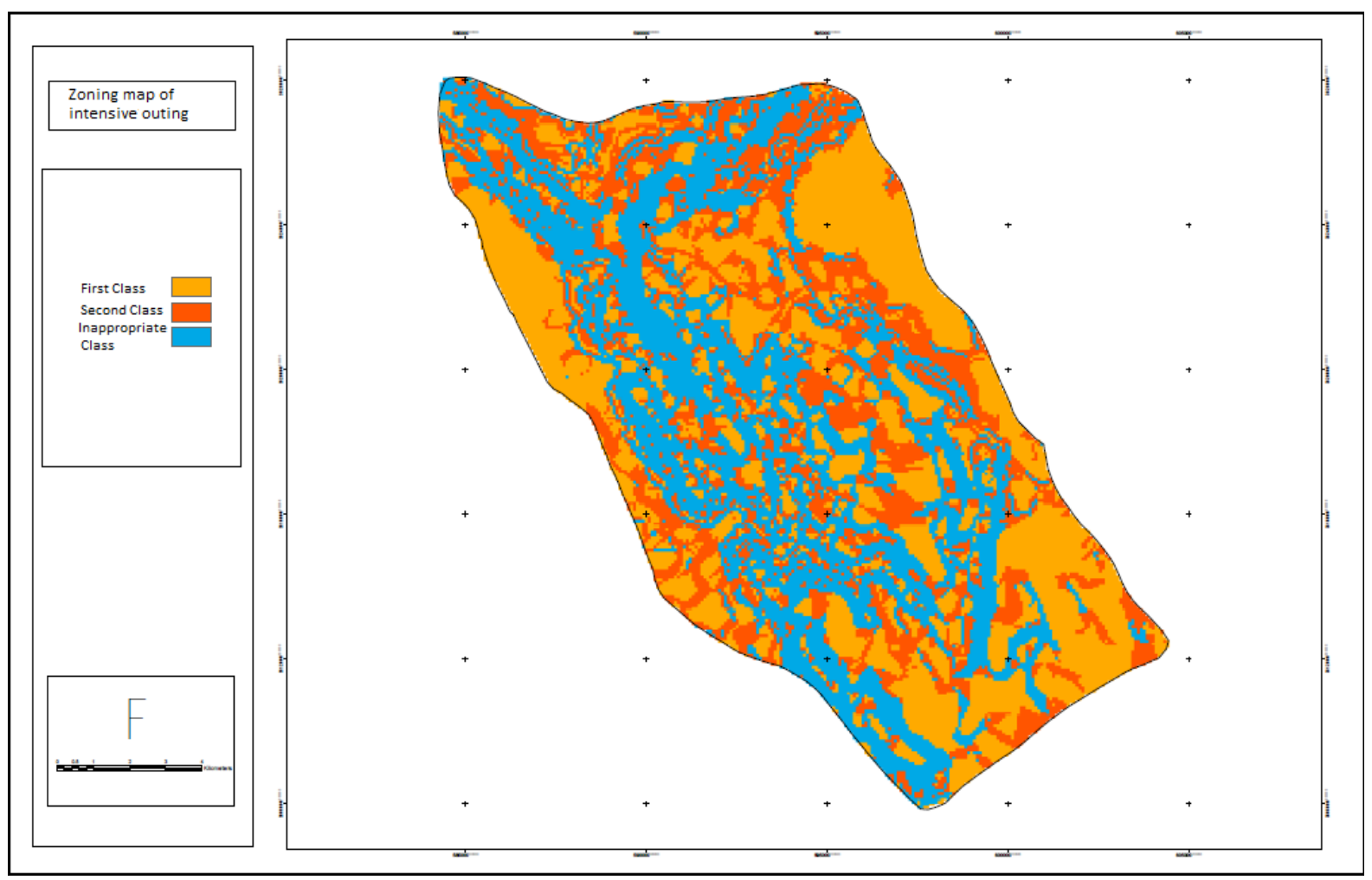

Figure 14. Intensive outing map.

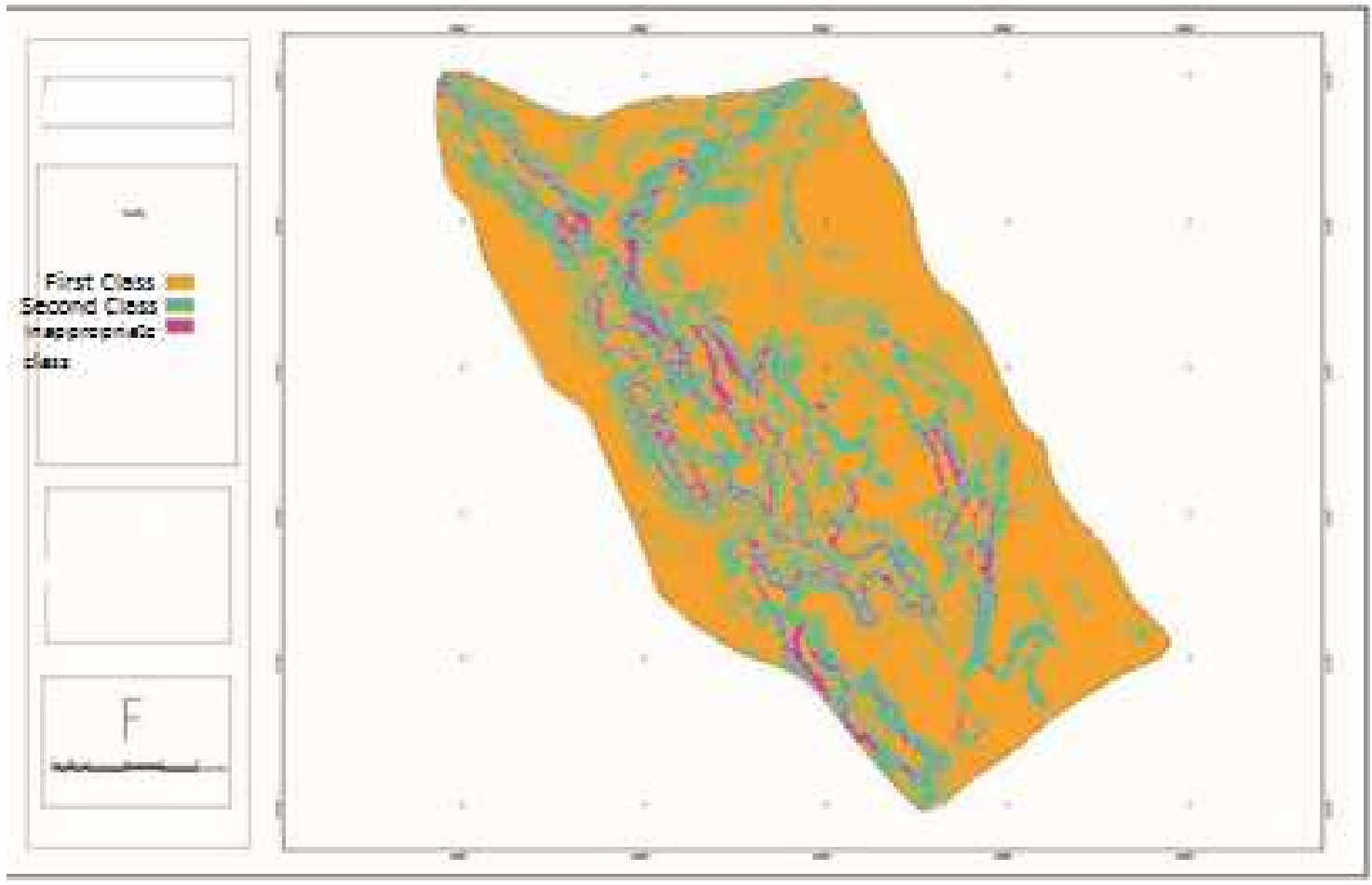

Figure 15. Extensive outing map.

Rijab mirage can be introduced as the most important ecotourism attractions of Kermanshah Province. According to the zoning map, mirages as one of the most interesting phenomena in karstic areas, because of very beautiful natural attractions (mountainous and temperate climate, diverse wildlife, Orphic vegetation, mountains, rivers, waterfalls, gardens, and valleys) in the distant past have caused great civilizations And these civilizations, considerably have developed cultural and historical monuments. Natural attractions, historical and cultural monuments in the Mirages basin have caused Mirages in Kermanshah Province to have major ecotourism attractions. 


\section{Conclusion}

Following ecological model of eco-tourism and comparison of ecological units in zoning maps of intensive outing, Qualified zoning map of extensive ecotourism has been presented. According to the results of the total area, 50 percent have potential to develop first level intensive ecotourism and 15 percent have potential to develop second level intensive ecotourism (fig.14).also, As we can get from above map, 80 percent of the region has ecological potential of first class extensive outing and 15 percent have second level ecological potential of extensive outing.

\section{References}

[1] Ahmadi, Majd.(2000), Distribution of geological formations in the watershed in Kermanshah, Natural Resources Research Center of Kermanshah Province.

[2] Afshar sistani, Iraj. (1992), Kermanshah and its ancient civilization, Vol.1, Zarrin Publications.
[3] Darvishsefat, Ali., Shetabi Jouybari, Sh.,and Sobhani, H.( 2004), Improvement of forest type classification by spectral data and auxiliary integration with determination of pre probability and creating spatial models of class occurrence, paper presented at the Conference on Geomatic.

[4] Ecotourism potentials of natural areas in Tehran, M.Sc. Thesis, Department of Geography, Earth Sciences, Shahid Beheshti University.

[5] Geography Book of Kermanshah Province, publishing textbooks, 2001.

[6] Makhdom, Majid, (2005), Land use footing, Tehran University Press, Sixth Edition.

[7] Ranjbarian, Bahram. (2000), Tourism planning at national and regional level, Jahad publications, First Edition.

[8] Zendehdel, Hasan, (2000), Iran at a glance, Irangardi publishing, Second edition. 